\title{
Primary and preschool immunisation in Grampian: progress and the 1990 contract
}

\author{
Lewis D Ritchie, Ann F Bisset, Daphne Russell, Valerie Leslie, Irene Thomson
}

\begin{abstract}
Objective-To examine changes in immunisation performance in Grampian region after the introduction of the 1990 contract for general practitioners.

Design-Retrospective descriptive study using data held on the Grampian immunisation record system's computer.

Setting-All 95 general practices in Grampian region ( 313 general practitioners).

Patients-All children in the primary immunisation and preschool booster age groups. This formed two groups of children for each of the four calendar quarters of 1990 and first three quarters of 1991 analysed as $(a)$ those aged 2 years on the first day of the relevant quarter and $(b)$ those aged 5 years on the first day of the relevant quarter, with an average population of 6600 and 6400 respectively.
\end{abstract}

Main outcome measure-Percentage immunised by practice.

Results-For primary immunisation the number of practices achieving immunisation rates of at least $95 \%$ increased from $29(31 \%)$ to $76(81 \%)$, and practices achieving $90 \%$ rates rose from $69(73 \%)$ to $87(93 \%)$. For preschool boosters, the number of practices achieving at least $95 \%$ immunisation rates increased from $22(23 \%)$ to $61(64 \%)$. By the end of September 1991, $76(80 \%)$ practices were achieving at least $90 \%$ levels compared with $36(39 \%)$ at the beginning of 1990 . Since the beginning of 1989 the proportion of immunisations not given by general practitioners declined from $14 \%$ to $2 \%$.

Conclusions-Primary and preschool immunisation rates for preschool children in Grampian showed a sustained improvement during 1990 and consolidation in 1991. Although overall trends were unchanged, 18 months after the introduction of the 1990 contract only one practice failed to meet lower target levels of $70 \%$ for both primary and preschool immunisation. By September 1991 more than three out of four practices had reached levels of at least $\mathbf{9 5 \%}$ for primary immunisation.

Grampian Health Board, Aberdeen AB9 8QP Lewis D Ritchie, MRCGP, consultant in public health medicine

Ann F Bisset, MA, registrar in public health medicine Valerie Leslie, BA, project leader, computing centre Irene Thomson, deputy registrar, primary care department

Department of Public Health, University of Aberdeen, Aberdeen Daphne Russell, MA, statistician

Correspondence to: $\mathrm{Dr}$ Ritchie.

BMF 1992;304:816-9

\section{Introduction} immunisation rates are at record levels. ${ }^{1} \mathrm{He}$ attributed this to various factors, including the introduction of immunisation targets in general practice and the publication of a readable guide to immunisation ${ }^{2}$ and the British Paediatric Association's manual on infection and immunisation. ${ }^{3}$

Information systems also seem important: a recent Department of Health study found that districts with high immunisation uptake rates had more accurate, up to date feedback on uptake related to general practices and clinics than did low uptake districts, ${ }^{4}$ and this was confirmed by experience in Fife, which showed that "professional education" was the best way to achieve a high level of immunisation coverage. ${ }^{5}$

Variation in medical practice has been focused on by the 1990 contract for general practitioners ${ }^{6}$; item of service payments have been replaced by target payments "to encourage general practitioners to achieve higher levels of cover for childhood immunisation." In February 1991 the secretary of state for health stated that four out of five general practitioners had achieved target payments for child immunisation and three out of four for preschool boosters. ${ }^{8}$ Audit of immunisation rates is therefore a topical issue.

Grampian has developed its own immunisation records system, known by the acronym of GIRS. As in other Scottish health boards, all patients registered with a general practitioner in Grampian are given a unique community health index number, which uses their date of birth, sex, and three other digits to make a unique number for each individual. This number is entered on computer. When immunisations are given, the information is sent to the health board's primary care department, where it is entered against the patient's number. Age limits are set for each immunisation and a default list is generated every three months for each practitioner, giving a printout of all children for whom there is missing or inappropriate information on immunisation. The general practitioner then updates these default lists and returns them to the primary care department.

The Grampian system differs from the standard immunisation recall system used elsewhere in Scotland in several ways. The major difference is that GIRS does not incorporate a call-recall mechanism, and therefore no letters of invitation are sent out to parents. For immunisation recording GIRS has proved useful in auditing general practitioners' performance ${ }^{9}$; giving feedback to general practitioners on their immunisation statistics and how these compare with those of other doctors; looking for clustering of parental and medical reasons for non-immunisation; and analysis of trends. A list of immunisation defaulters is prepared quarterly, and complementary graphic feedback comparing each general practitioner to the practice and Grampian averages is produced, with a commentary by the department of public health medicine. GIRS has more recently been used to monitor changes in immunisation practice, including the introduction of the new contract in April 1990.

In a recent $B M \mathcal{F}$ editorial Rudd observed that

\section{Methods}

The study comprised all general practices in Grampian and a few in north Tayside with registered patients who had Grampian addresses - a total of 95 practices and 313 principal general practitioners. The groups of children studied were all those aged 2 years or 5 years on the first day of the quarter analysed (an average of 6600 and 6400 children, respectively). The study design was a retrospective descriptive survey using data held on the Grampian immunisation record system's computer. A computer analysis was obtained for each general practice of the number of children in the practice group to be immunised and the percentage immunisation rate for each practitioner and for each practice. The percentage immunisation rate for each practice was calculated for the seven quarters ending on the last day of March 1990, June 1990, September 1990, December 1990, March 1991, June 1991, and September 1991. Separate analyses were done for children aged 2 and 5 . 
Statistical analysis was performed with the SPSS/ $\mathrm{PC}+3 \cdot 1$ software package, ${ }^{10}$ incorporating linear, nonlinear, and logistic regressions; analysis of variance; Wilcoxon and $\chi^{2}$ tests.

\section{Results}

For the whole of Grampian the immunisation rate for 2 year olds at 30 September 1991 was $98.0 \%$ for diphtheria, tetanus, and polio; $95.0 \%$ for pertussis; and $96.8 \%$ for measles, mumps, and rubella. The average immunisation rate was $96.8 \%$ (fig 1 ). The corresponding rate for the preschool diphtheria and tetanus immunisation and polio booster was $93.9 \%$ (fig 2). Both graphs indicate increasing uptake over several years. Figure 1 shows that there was no change in trend after the introduction of the contract. A logistic regression model fitted the trend in each of the three primary immunisations, with evidence of stabilisation in 1991. Figure 2 shows a seasonal pattern. Analysis of variance incorporating a linear trend with regular seasonal variations showed an excellent fit for 1987-9. Comparison of later values with predictions based on this model gave no evidence that the overall linear trend has changed, although the seasonality is decreasing.

An assessment of the changes in immunisation rates over the seven quarters from the beginning of January 1990 to the end of September 1991 was undertaken and is summarised in figures 3 and 4 . The number of practices achieving at least $95 \%$ immunisation rates of 2 year olds rose from $29(31 \%)$ practices to $76(81 \%)$. By the end of the last quarter seven $(7 \%)$ practices were achieving less than the $90 \%$ target level compared with $25(27 \%)$ in the first quarter. One practice failed to meet the $70 \%$ target at the end of the period compared with three at the beginning. Comparison of the first and second quarters showed that a significant change in uptake took place in the quarter following introduction of the 1990 contract $(p<0 \cdot 0001$, Wilcoxon matched pairs test). There was a much smaller improvement in the next quarter $(p<0.05$, Wilcoxon test $)$, but no significant change was observed in succeeding quarters.

For the preschool immunisation, the number of practices achieving at least $95 \%$ immunisation rates rose from $22(23 \%)$ to $61(64 \%)$. By the end of September 1991, $19(20 \%)$ practices failed to meet the $90 \%$ target level compared with $57(61 \%)$ at the outset. Three (singlehanded) practices did not attain the $70 \%$ level in the third quarter of 1991 compared with 10 in the first quarter of 1990 . Progress was more striking

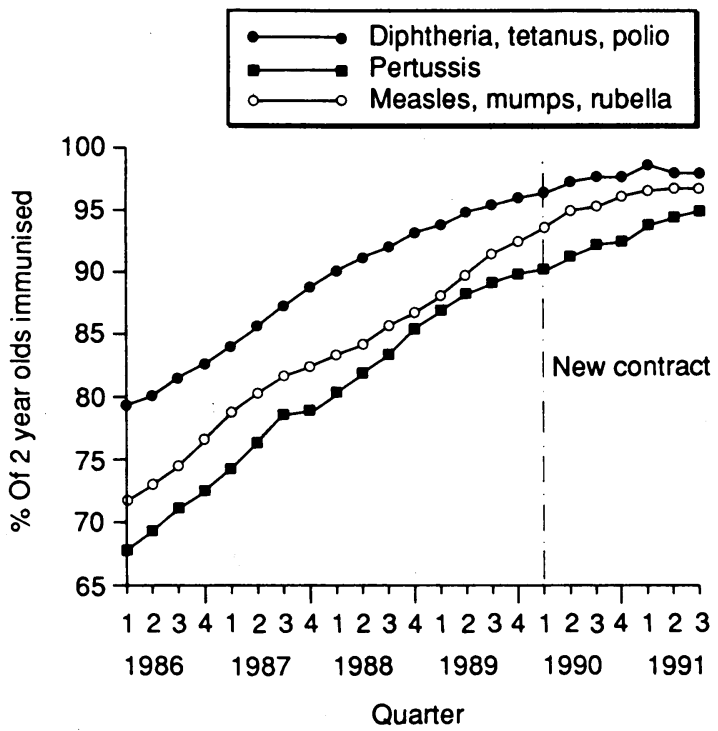

FIG 1 -Percentage of children aged 2 years (average group size 6600) given primary immunisation in Grampian region, 1986-91

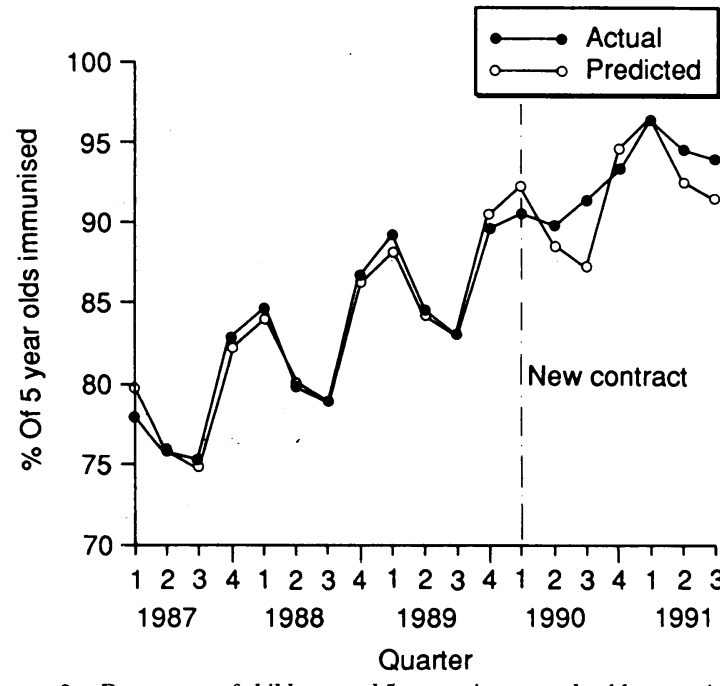

FIG 2-Percentage of children aged 5 years given preschool boosters in Grampian region, 1987-91

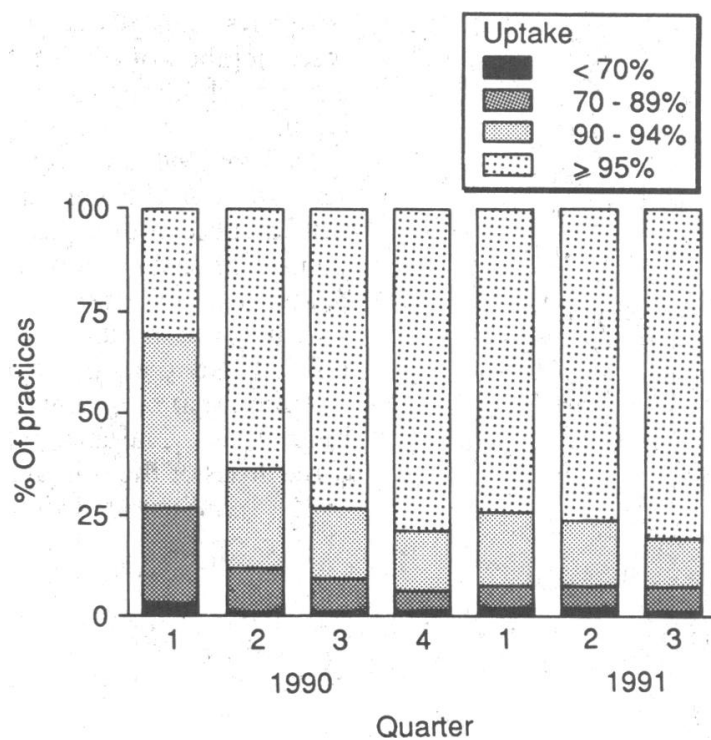

FIG 3-Uptake of primary immunisation in 94 practices in Grampian region, 1990-1

but also more gradual for 5 year olds, with successive improvements in every quarter in 1990. The difference between the first two quarters of 1990 was not significant, but it was highly significant in the next two quarters $(p<0.001$, Wilcoxon test) and was followed by a small but significant deterioration between the first and second quarters of 1991 ( $p<0.0001$, Wilcoxon test).

Immunisations were analysed according to whether they were performed by general practitioners or by others. The percentage of immunisations carried out by others (mainly community child health doctors) decreased (fig 5), but the major and continuing decline began immediately before the 1990 contract was introduced. Community child health doctors were carrying out $12 \cdot 1 \%$ of immunisations in the third quarter of 1986 and $11.5 \%$ in the corresponding period in $1989,5 \cdot 7 \%$ in 1990 , and only $2 \cdot 2 \%$ in 1991 .

Immunisation performance was assessed in relation to the number of children in relevant age groups and practice characteristics. There seemed to be no obvious relation between immunisation rate and numbers of children to be immunised. Practice location (urban, rural, or mixed) seemed to have no consistent influence on uptake. Partnership size may affect immunisation performance. In the third quarter of 1991 for primary immunisation $22 \%(5 / 23)$ of singlehanded practices achieved rates under $90 \%$ compared with $3 \%(2 / 71)$ of non-singlehanded practices $(\mathrm{p}=0 \cdot 009$, Fisher's exact 
test; $95 \%$ confidence interval for $19 \%$ difference between percentages, $1 \cdot 6 \%$ to $36 \cdot 2 \%$ ); corresponding figures for preschool boosters were $24 \%(6 / 25)$ and $19 \%$ $(13 / 70)(p=0.81 ; 5 \%(-13 \cdot 6 \%$ to $24 \cdot 5 \%)$ difference). All five of the singlehanded practices that achieved primary immunisation rates under $90 \%$ also did not attain this level for preschool boosters.

One obvious factor in ensuring accurate assessment of immunisation rates is to keep up to date records and to remove from the records patients who have left the practice or area. There were 98 removals of untraced children aged 0-5 years, between April 1988 and March 1989,150 in this period 1989-90, and 127 in 1990-91, constituting $<0.4 \%$ of the entire group in each year. Removal of untraced children - "ghostbusting"-does not seem to have been influenced by the 1990 contract or to have contributed to improved immunisation rates.

The number of children removed from lists at the request of general practitioners has remained very low. For children aged 5 and under, only six boys and three girls were taken off the list in 1990-1 compared with two boys and two girls in 1989-90. These children were members of whole families who had been removed and not children who had defaulted from immunisation.

In May 1990 an accelerated primary immunisation schedule was introduced in England and Wales with the first dose of diphtheria, tetanus, and pertussis and polio to be given at 2 months of age, the second dose at 3 months, and the third dose at 4 months. This schedule was notified in Scotland in early 1990 and officially adopted in October 1990, with the stated intention that the primary course would be completed by 26 weeks. The changing average age at giving of the three doses of the primary course in Grampian during 1986-91 is illustrated in figure 6. A slow decline over

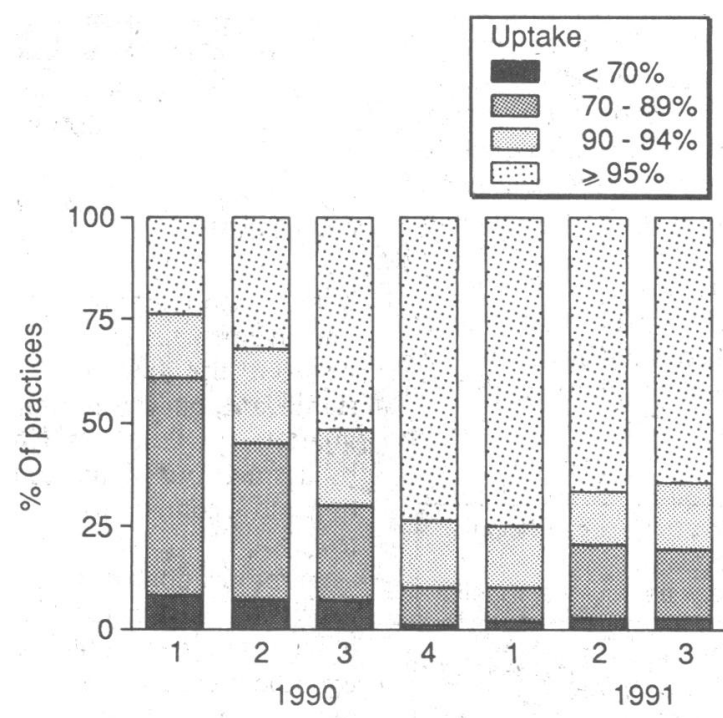

Quarter

FIG 4-Uptake of preschool immunisation in 95 practices in Grampian region, 1990-1

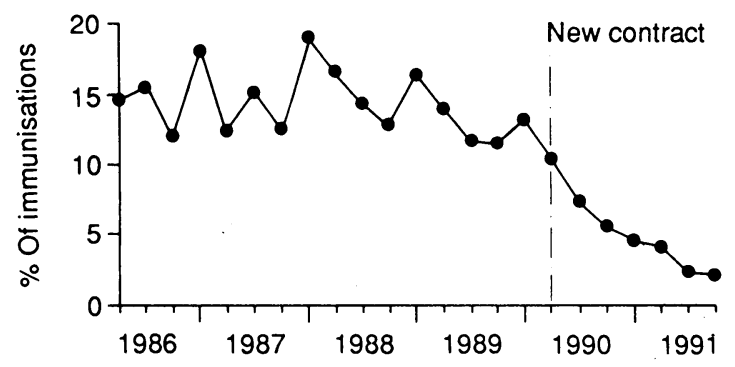

FIG 5-Percentage of primary and preschool immunisations not given by general practitioners, Grampian region, 1986-91

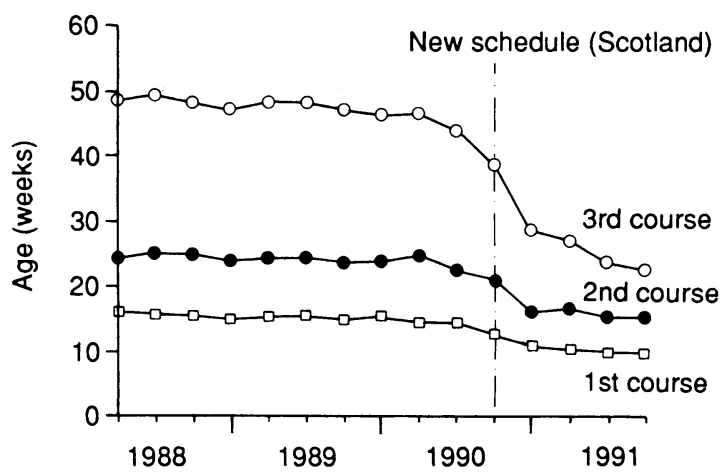

FIG 6-Average age of children given primary diphtheria, tetanus, and pertussis and polio immunisation, Grampian region, 1988-91

the first four years suddenly accelerated at the start of 1990. In January 1990 the average age at completion was $47 \cdot 3$ weeks; it dropped to $38 \cdot 6$ weeks by September 1990 and 22.4 weeks by September 1991 . This indicates successful implementation of the new schedule, which began before the official date of adoption. (Regression analysis also showed evidence of later non-linearity with a decrease in slope after January 1991.)

\section{Discussion}

Replying to Rudd's editorial,' Wrench et al emphasised that the steady improvement in immunisation rates over several years cannot be attributed to recent innovations such as targets in the 1990 contract or to the availability of better professional guidelines. "This is apparent in figures 1 and 2 , which mirror the national statistics. " We agree that the reasons for the improvements are complex and include much hard work by, and superior educational materials for, all professionals involved-particularly general practitioners, health visitors, community child health doctors, and local immunisation coordinators. Similarly, improved health board and health district information systems, installation of practice computers, and stimulation of parental knowledge may have contributed. All of these were taking place in Grampian region before the introduction of the 1990 contract.

The higher immunisation rates in 1990-1 may be simply seen as a continuation of pre-existing trends, and it would seem that the 1990 contract has had little effect (figs 1 and 2). Nevertheless, it becomes progressively more difficult to improve on immunisation rates that are already high.

District or area average immunisation rates can mask widespread differences between practices. ${ }^{12}$ The improvements in performance during 1990 and 1991 are therefore best seen at practice level for primary immunisation (fig 3 ) and for preschool boosters (fig 4): $81 \%$ of practices for primary immunisation and $64 \%$ of practices for preschool boosters had achieved at least 95\% immunisation rates by the end of September 1991. This suggests that the new target levels of 95\% proposed in The Health of the Nation ${ }^{13}$ may be attainable.

Further evidence of changed behaviour is provided by the increase in proportion of immunisations given by general practitioners rather than community child health doctors (fig 5). (Reid et al in a similar study on cervical screening in Tayside also observed a greater proportion of procedures being done recently by general practitioners and noted a potential threat to the viability of community clinics. ${ }^{14}$ ) It may be possible to redeploy community child health doctors in the role of "immunisation facilitators" to lend active support to general practitioners working in practices with lower levels of uptake.

Many aspects of the 1990 contract have resulted in controversy and heated debate. Concern has been 
expressed that general practitioners might deliberately remove patients from their lists if they did not comply with offers of immunisation, placing target payments in jeopardy.$^{15}$ There is no evidence for this in Grampian. Only nine patients aged 5 years or under were removed, compared with four for the previous year, and these were members of families who had been taken off the list for other reasons. Active monitoring and removal of untraced patients have had negligible effects on immunisation rates in Grampian region but this may not be the case elsewhere - for example, in some inner city areas with highly mobile populations. ${ }^{16}$

Our survey suggests that recent uptake rates in Grampian are not significantly influenced by size of group to be immunised and location of practice, but our findings may be atypical- $\mathrm{Li}$ and Taylor have recently observed that children resident in rural and suburban areas had greater uptakes than those in inner cities. ${ }^{17}$ A greater proportion of singlehanded practices did not attain $90 \%$ target levels, but this was not statistically significant for 5 year olds. This finding should be interpreted with caution in view of the small numbers involved. However, a simple assessment of immunisation rates masks the fact that some general practitioners and health visitors may have had to work much harder to obtain a good uptake "in the face of socioeconomic deprivation and parental uncertainty." This is reinforced by Jones and Moon, who have suggested that crude uptake rates are inadequate performance indicators. ${ }^{19}$

The successful introduction of the accelerated primary immunisation schedule may have been assisted by the requirements of the 1990 contract. In turn, the schedule should operate to the benefit of realising target payments by allowing a longer period to catch up on defaulters.

General practitioners, health visitors, community health doctors, and administrative staff in Grampian have worked hard to improve immunisation rates. The effects of the 1990 contract seem encouraging, but outstanding anomalies-for example, non-payment for immunisations given to children outside target groups $^{20}$ - need to be remedied. Eliminating preventable infections by immunisation remains the prime objective and there is still much work to be done.

We thank Dr Angela Maxwell, Dr John Curnow, Mrs Cathy Fleming, Mrs Diane McGregor, Mrs Mary Humphrey, and Mrs Moira Napper for their help in preparing this article. We also acknowledge the original support work provided by Dr J G Paterson, Mrs Jackie Fleming, and colleagues in Grampian Health Board Information Services Group and ongoing assistance from staff in the computer department.

1 Rudd PT. Childhood immunisation in the new decade. BMf 1991;302:481-2. 2 Department of Health, Welsh Office, Scottish Home and Health Department.

Immunisation against infectious disease. London: HMSO, 1990 .
3 Nicoll A, Rudd PT, eds. British Paediatric Association manual on infections and immunisations in children. London: British Paediatric Association, 1989.

4 British Market Research Bureau. The uptake of preschool immunisation in England: report on a national study of variation in immunisation uptake between England: report on a national study of variation in
district health authorities. London: BMRB, 1989.

5 Walker D. Immunisation rates in general practice. BMF 1989;299:458.

6 Quam L. Improving clinical effectiveness in the NHS: an alternative to the white paper. $B M \mathcal{F}$ 1989;299:448-50.

7 Health Departments of Great Britain. General practice in the National Health Service: the 1990 contract. London: Department of Health and Socia Security, 1989.

8 Beecham L. Taking the bureaucracy out of the GP contract. BMF 1991;302: 367

9 Bisset A, Thompson I. Use of computerised records to ensure optimum measles vaccination. Health Bull (Edinb) 1990;48:294-8.

10 SPSS Inc. SPSS/PC + version 3.1-user's guide. Chicago: SPSS Inc, 1990.

11 Wrench J, McWhirter M, Pearson S. Childhood immunisation. BMf 1991;302:787-8.

12 Narayan KMV. Measles mumps and rubella vaccine coverage. Lancet $1989 ; \mathrm{i}: 271-2$.

13 Secretary of State for Health. The health of the nation. London: HMSO, 1991.

14 Reid GS, Robertson AJ, Bisset C, Smith J, Waugh N, Halkerston R. Cervical screening in Perth and Kinross since introduction of the new contract. BMf screening in Perth
1991;303:447-50.

15 Adams B, Appleby J. Healthcare data briefing: variations in immunisation. Health Services fournal 1990;100:1176.

16 Jefferies S, McShane S, Oerton J, Victor CR, Beardow R. Low immunisation uptake rates in inner-city health district: fact or fiction? I Public Health Med 1991;13:312-7.

$17 \mathrm{Li} \mathrm{J}$, Taylor B. Comparison of immunisation rates in general practice and child health clinics. $B M \mathcal{F}$ 1991;303:1035-8.

18 Nicoll A, Elliman D, Begg NT. Immunisation: causes of failure and strategies and tactics for success. BMF 1989;299:808-12.

19 Jones K, Moon G. Multilevel assessment of immunisation uptake as a performance measure in general practice. $B M 7$ 1991;303:28-31.

20 Walker D, Coid D, Jones IG. Childhood immunisation. BMJ 1991;302:787.

(Accepted 3 fanuary 1992)

\section{Trends in hospital admission rates for asthma in children}

\section{David P Strachan, H Ross Anderson}

Department of Public

Health Sciences, St

George's Hospital Medical

School, London SW17 0RE

David P Strachan, MD, senior

lecturer in epidemiology

$\mathrm{H}$ Ross Anderson, MD professor of clinical

epidemiology

Correspondence to:

Dr Strachan.

BMF 1992;304:819-20
Rates of admission for childhood asthma in England and Wales have more than doubled since the mid1970 s,' but it is unclear whether this reflects an increase in the prevalence or severity of wheezing or changes in medical care. ${ }^{2}$ The mortality from asthma in children has changed little over this period. ${ }^{2}$ We report findings from two identical surveys of schoolchildren in south London during 1978 and 1991 which explore changes in the prevalence of disease and utilisation of services.

\section{Subjects, methods, and results}

In February 1978 and February 1991 the same one page questionnaire was circulated to the parents of all children aged $71 / 2$ to $81 / 2$ years attending public and private schools in the London borough of Croydon. Parents were asked, "Has your child ever had asthma?" and "Has he/she ever had attacks of wheezing in the chest?" Those responding positively to either question were asked whether the child had had attacks of asthma or wheezing in the past year. Further information was requested if this was so (see table).

Response rates were $87 \%(4147 / 4763)$ in 1978 and
$81 \%(3070 / 3786)$ in 1991. Comparison of early and late respondents and schools with high and low response rates in the 1991 survey suggested minimal bias due to non-response. The proportion of children affected by wheezing in the past year increased slightly from 1978 to 1991 , but the prevalence of frequent attacks (five or more a year) was unchanged (table). School absence attributable to wheezing was less common in 1991 . Twice as many wheezy children had been diagnosed as asthmatic in 1991 as in 1978. Slightly more wheezy children were receiving treatment from the general practitioner in 1991 than in 1978 whereas outpatient supervision was somewhat less common. Use of casualty departments was greatly increased whereas home visits by general practitioners, particularly to children with frequent wheeze, had declined.

Admission rates for childhood asthma in Croydon have followed recent national trends. Hospital Activity Analysis data for 1977 show 57 emergency admissions (22.4 per 10000) among Croydon residents aged 5-9 years admitted to any hospital in the South Wes Thames region. The corresponding figures for 1990 (hospital episode system data) are 83 admissions (43.9 per 10000).

\section{Comment}

Few studies have used a standard methodology to investigate time trends in childhood asthma in Britain. ${ }^{3.5}$ Our surveys are the first to measure changes in medical care and utilisation of services. These were 